Matthew Haug*

\title{
Must Naturalism Lead to a Deflationary Meta-Ontology?
}

\begin{abstract}
Huw Price has argued that naturalistic philosophy inevitably leads to a deflationary approach to ontological questions. In this paper, I rebut these arguments. A more substantive, less language-focused approach to metaphysics remains open to naturalists. However, rebutting one of Price's main arguments requires rejecting Quine's criterion of ontological commitment. So, even though Price's argument is unsound, it reveals that naturalists cannot rest content with broadly Quinean, “mainstream metaphysics,” which, I suggest, naturalists also have independent reasons to reject.
\end{abstract}

Keywords: meta-ontology, naturalism, Huw Price, ontological commitment, W.V.O. Quine

DOI $10.1515 / \mathrm{mp}-2014-0021$

According to a standard potted history of twentieth-century philosophy, W.V.O. Quine made the world safe for metaphysical inquiry again, in part by offering a definitive refutation of Rudolf Carnap's deflationary view of metaphysics. Quine is thus commonly taken to have provided much of the framework for "mainstream” analytic metaphysics (Manley 2009, 3-4; van Inwagen 1998, 2009). This approach to metaphysics takes ontological disputes to be substantive debates about the nature of the world, rather than merely verbal, conceptual, or pragmatic disputes. According to Quine, metaphysical debates are to be adjudicated using the same methods used to settle debates within science: namely, by evaluating competing theories with respect to global theoretical virtues, such as simplicity, explanatory power, and integration with other theories (see, e.g. Sider 2011, esp. 166ff.). It is this continuity between natural science and metaphysics that is the primary reason that Quinean metaphysics is regarded as naturalistic. ${ }^{1}$

1 Cf. Quine's famous claim that "Ontological questions, under this view, are on a par with questions of natural science” $(1951,45)$.

*Corresponding author: Matthew Haug, Department of Philosophy, The College of William \& Mary, P.O. Box 8795, Williamsburg, VA 23187-8795, USA, E-mail: mchaug@wm.edu 
Quine's approach to metaphysics is often taken to motivate the idea that the ontology we should accept is the one that turns out to be required by science. Following Huw Price, we can call this (the ontological version of) object naturalism - that "all there is is the world studied by science" (2004, 185, italics in original). Of course, it is not obvious how, if at all, purported entities in a variety of domains - especially what Price calls "M-worlds": morality, meaning, mathematics, and mentality - fit into the "world studied by science" (Price 1997). Thus, object naturalism motivates "placement problems" with respect to these domains. ${ }^{2}$

In a series of papers, Huw Price has argued that a proper understanding of naturalism inevitably leads to a more deflationary approach to placement problems and to ontological questions in general. ${ }^{3}$ According to his "ontological quietism," or what I'll call "ontological deflationism," there is no "separate second-order science of ontology," and the ontologist rests content with "the mundane business of existential quantification carried out by first-order specialists in the course of their working lives" $(1992,50) .^{4}$

One of Price's two main routes from naturalism to ontological deflationism begins with the claim that naturalists should focus on how we humans talk about apparently non-naturalistic domains, instead of the purported referents of this talk. $^{5}$ Price claims that this focus raises serious problems with what he calls "Representationalism" - the idea that language mirrors the world via substantive semantic relations (2004, 189; 2011a, 5-6, 10-11). By abandoning Representationalism, we can see that superficially descriptive language serves a wide variety of functions. (This is Price's "functional pluralism," to which I return below (cf. Price 1997, 136).) Describing the functions of discourse about the different M-worlds, and how these functions differ from those of scientific

2 See Jackson (1998) for an influential statement of the idea that one of the main tasks of "serious metaphysics" is to solve placement problems and an equally influential account of how to go about solving them, which has come to be called the "Canberra Plan."

3 Many of these papers are collected in Price's (2011b). Jenann Ismael $(2013,86)$ has recently dubbed Price's approach the "Sydney Plan" in order to contrast it with "the most influential self-proclaimed naturalistic approach" to metaphysics - the Canberra Plan - which endorses object naturalism.

4 As Thomasson (2013, 111-12) notes, care must be taken in interpreting "deflationary." She claims that this kind of deflationism deflates the ontological debates about entities, not the entities themselves. Hence, proponents might prefer the label "meta-ontological deflationism," reserving the term "simple realism" or "minimal realism" for their first-order ontological view. (See also Price (1992, 49-52).)

5 I adopt Price's geographical metaphor of "routes" or "paths" to ontological deflationism - a "location on the contemporary philosophical map" that Price claims is both "easily accessible from familiar and popular places" but also "almost invisible, almost unvisited," in part because of the intuitive appeal of Representationalism (2011a, 11). 
discourse, is all that it is needed to solve (or, better, dissolve) placement problems. In particular, there is allegedly no further factual question about whether moral, mental, meaning, or mathematical properties "really" exist. And there is no need to find truthmakers for discourse about such apparently non-naturalistic domains - no need to pursue metaphysics on a "matching game" model (Price 2011a, 3-6). Thus, Price's deflationary approach allegedly offers a naturalistic explanation of "how topics such as morality and meaning might remain high and dry, untouched and unthreatened by the rise of the scientific tide" without having to locate morality or intentionality in the natural world (Price 1997, 133).

In the first section following this introduction, "Subject naturalism need not be 'prior to' object naturalism”, I argue that naturalists have an escape route from this path to ontological deflationism; they can adopt a non-linguistic, "material," approach to metaphysical inquiry, against which, I argue, Price provides no convincing argument. In the first sub-section, "The material conception as a default assumption", I argue that the material approach is merely a starting point for metaphysical inquiry, and thus, contra Price, does not unjustifiably ignore competing non-cognitivist approaches. Further, as I argue in the second sub-section, "The role of semantic notions in metaphysics", there are questions about at least some M-worlds that remain unaddressed by his exclusively linguistic approach but which the material approach handles adeptly. ${ }^{6}$ So, pace Price, the linguistic approach does not have the upper hand even in the absence of a general argument for object naturalism.

In the second main section, "Quine and Carnap on ontology”, I discuss how Price can turn to his second path from naturalism to ontological deflationism to attempt to block this escape route. This second path focuses on the debate between Carnap and Quine over metaphysical methodology. Quine's criterion of ontological commitment does call for a linguistic approach to ontological debates. So, if we accept this criterion, moving from claims about language to object naturalist claims about the world is embroiled with the substantive semantic notions invoked by, and the problems facing, Representationalism. Price focuses, though, on an additional challenge facing non-deflationary Quinean metaphysics. He claims that it is not acceptable by Quine's own naturalistic lights, for it would make substantive metaphysics a "second-order" inquiry outside of science. Thus, Price argues that Quine's naturalism in fact motivates a "pale," deflationary metaphysics of the kind that Carnap favored (Price 2007, 2009).

6 Of the M-worlds, mentality seems to pose the most difficulty for Price's deflationary approach in this regard. See the sub-section, "The role of semantic notions in metaphysical inquiry", and notes 9 and 11 . 
As I discuss in the first sub-section, "Blocking the move from minimal deflationism to ontological deflationism", naturalists can avoid the second route to ontological deflationism if they abandon Quine's criterion of ontological commitment. Fortunately, as I point out in the second sub-section, "Naturalistic reasons to reject Quine's criterion of ontological commitment”, they have independent, naturalistically motivated reasons for doing so. Both of these points suggest that Quine's reformation of metaphysics was inadequate by the standards set by his own naturalistic program.

In the third and final main section, "A sketch of non-deflationary naturalistic metaphysics”, I outline an alternative, non-deflationary naturalistic approach to ontology. Importantly, abandoning Quine's criterion of ontological commitment allows us to offer oblique answers to some ontological questions, capturing the grain of truth in skeptical attitudes toward (some of) metaphysics without requiring full-blown ontological deflationism.

\section{Subject naturalism need not be "prior to" object naturalism}

Price contrasts Quinean “object naturalism," as introduced above, with his preferred version, "subject naturalism," which follows Hume and Nietzsche in thinking that "philosophy needs to begin with what science tells us about ourselves" (2004, 186, italics in original). Subject naturalism is "the philosophical viewpoint that begins with the realization that we humans (our thought and talk included) are surely part of the natural world” (2011a, 5). Thus, “[subject naturalism] adopts the scientific perspective of a linguistic anthropologist, studying human language as a phenomenon in the natural world" (2011a, 11; 2011b, xi).

Given this characterization, one might think that subject naturalism does not really compete with object naturalism. As Price points out, object naturalists will insist that they are subject naturalists too. For, from their perspective, subject naturalism is merely a corollary of object naturalism (2004, 186). "After all, if all real entities are natural entities, we humans are surely natural entities" (2004, 186).

Price argues that this is mistaken. In a nutshell, he claims that object naturalism presupposes an account of the relation between language and the world (Representationalism) that is part of the purview of subject naturalism. This is what he calls the priority thesis - that "subject naturalism is theoretically prior to object naturalism because the latter depends on validation from a subject naturalist perspective" (2004, 186). Further, he thinks that there are 
good reasons to doubt whether Representationalism will be validated from a subject naturalist point of view. This is what he calls the invalidity thesis. In his view, there is reason to think that subject naturalism will reveal that the object naturalist approach is untenable $(2004,187)$.

I shall argue that Price does not provide a convincing argument for the priority thesis, which renders his worries about Representationalism otiose. Object naturalism need not presuppose Representationalism, so it is not undermined if Representationalism turns out to be false. ${ }^{7}$

To see how object naturalists can avoid Price's attack we need to introduce his distinction between two conceptions of how to approach placement problems: the material conception and the linguistic conception. On the material conception, we are confronted with some alleged phenomenon or entity - such as intentionality, consciousness, or moral goodness - and in light of a commitment to object naturalism, come to wonder how this phenomenon or entity could fit into the natural world. On the contrasting, linguistic conception,

the starting point lies in human linguistic practices, broadly construed. Roughly, we note that humans (ourselves or others) employ the term " $X$ " in language, or the concept $X$, in thought. In the light of commitment to object naturalism, again, we come to wonder how what these speakers are thereby talking or thinking about could be the kind of thing studied by science. (Price 2004, 188)

Given the linguistic conception, object naturalists must find a way to move from the term " $\mathrm{X}$ " (or concept $X$ ) to its supposed object, $\mathrm{X}$ - to move from claims about language (or thought) to claims about the world. That is, they must invoke Representationalism. Thus, according to Price, object naturalism "rests on substantial theoretical assumptions about what we humans do with language roughly, the assumption that substantial 'word-world' semantic relations are a part of the best scientific account of our use of the relevant terms" (Price 2004, 190). But this assumption is exactly the kind of thing that subject naturalism investigates. Thus, given a linguistic conception of the origin of placement problems, subject naturalism is prior to object naturalism.

7 Penelope Maddy's Second Philosopher is an example of someone who endorses semantic deflationism (and thus would reject Representationalism) but rejects ontological deflationism. "[W]hen the question is ontology, her focus is on what there is, not on what various people are inclined to think or say there is" (Maddy 2007, 399). Further, she does not rest content with the quantification of other "first-order specialists." "Second Metaphysics is emphatically not a purely descriptive enterprise: the Second Philosopher holds [definite views about when the existence of atoms was established], not merely that scientists thought this or that at various times” (2007, 403). See the sub-section, “Naturalistic reasons to reject Quine's criterion of ontological commitment", below. 
Price now turns to defending the invalidity thesis. He outlines three significant worries that threaten to undermine Representationalism: (a) semantic deflationism may be true (2004, 191-2), (b) even non-deflationary semantic notions may be too indeterminate to do the work required by object naturalism (2004, 192), and (c) it is unclear if the semantic notions themselves can be investigated from the viewpoint of object naturalism (2004, 192-5).

I agree that these are serious worries for Representationalism. However, they pose a challenge to object naturalism only if the linguistic conception of placement problems is correct. As noted above, and as Price acknowledges, the above argument for the priority thesis (on which, in turn, the invalidity thesis depends) goes through only if the linguistic conception is true $(2004,188-9,190)$. Thus, he must argue against the material conception of placement problems. Here I think that Price is on much shakier ground. ${ }^{8}$

\section{The material conception as a default assumption}

Price has two main arguments against the material conception. The first is that adopting the material conception requires one to ignore, or rule out, any noncognitivist dissolution of placement problems (Price 2004, 188, 195). If standard use of the term " $\mathrm{X}$ " did not have a referential function, then there would simply be no material problem about the purported X. Equivalently, if the material conception were correct, then the use of the term " $X$ " would be referential. This would allegedly show that non-cognitivism "is not so much wrong as completely wrongheaded - a view which simply starts in the wrong place” $(2004,188)$.

Couldn't the object naturalist simply insist that non-cognitivism is "wrongheaded"?" Price claims that this is a "radically anti-naturalistic move," for it is allegedly to "simply ignore the possibility that philosophy might have something to learn from naturalistic - subject naturalistic - reflection on the things that humans do with language" (2004, 196, italics in original). In other words, Price claims that adopting the material conception would amount to claiming that non-cognitivism should not even be acknowledged as an admissible linguistic hypothesis. And this, Price claims, would be an anti-naturalistic attempt to rule a priori on an issue that is the subject of ongoing scientific investigation into human language use.

8 Price admits that he argues "somewhat tentatively" that the material conception is not a live option for object naturalists $(2004,189)$. If my discussion is on the right track, his tentativeness is warranted.

9 At least for some areas of discourse - some of Price's "M-worlds"? Non-cognitivism is far less attractive for discourse about the mental than, say, for moral discourse. 
I see no reason to think that the material conception is anti-naturalistic in the way that Price suggests. The material conception is merely a starting point for, or default assumption about, metaphysical inquiry, not a claim about where such inquiry must end up. Those who adopt the material conception think that it is unlikely that "naturalistic reflection on what we humans do with language" will support non-cognitivism (at least across the board; see notes 6, 9, and 11). And they think that non-cognitivist approaches to placement problems should be pursued only after cognitivist ("object-oriented" or "material”) approaches have failed. Further, they think that these methodological recommendations are supported by the fact that discourse about the M-worlds is prima facie cognitive (hence the "default" nature of the assumption) and by the fact that there are well-known semantic difficulties, such as the Frege-Geach (or "embedding”) problem, with non-cognitivist approaches. However, as good fallibilists, they are willing to revise this assessment as new evidence comes in or if cognitivist approaches prove unworkable.

Note also that if the material conception were anti-naturalistic in the way Price identifies, then his own approach would be anti-naturalistic in the very same way. For, Price's approach views all of language with an ironic detachment whose "default assumption" is always that the apparent ontological commitments of our discourse "should not be taken at their face value" (2011a, 30). A proponent of the material conception might claim that this ignores, or rules out, the possibility that $\mathrm{M}$-world predicates straightforwardly express objective properties - that it implies that cognitivism "is not so much wrong as completely wrongheaded" - and is thus an a priori attempt to close off legitimate avenues of exploration in "linguistic anthropology." However, this complaint would make the same mistake that Price does. The linguistic conception, like the material conception, is merely a recommendation for how to begin a metaphysical research program, not the end product of such a program. In general, such recommendations need not be neutral with respect to every possible competing recommendation. Of course, if one's default assumptions are merely tacit and go unrecognized, then there is a real danger that incompatible views will be invisible and go unexplored. However, this is not a worry here, given that Price has made these competing assumptions explicit.

\section{The role of semantic notions in metaphysical inquiry}

Price's second argument against the material conception begins by noting that semantic notions are "part of the toolkit" of (at least the most influential approaches to) contemporary metaphysics $(2004,196)$. Given this, he argues 
that object naturalists face a dilemma. Either substantive semantic notions are involved in metaphysics, in which case the challenges to Representationalism outlined above rear their heads, or only deflationary semantic notions are involved in metaphysics. In the latter case, Price claims that the object naturalist no longer has the materials to offer a general argument for her position (the kind of argument that would parallel causal-explanatory arguments for physicalism), and thus has no advantage over her subject naturalist opponents (2004, 197). As Price puts it, such an object naturalist is vulnerable to the subject naturalist

who takes advantage of a non-representationalist theoretical perspective to avoid the material mode altogether. If such an opponent can explain why natural creatures in a natural environment come to talk in these plural ways - of "truth," "value," "meaning," "causation," and all the rest - what puzzle remains? What debt does philosophy now owe to science? $(2004,198)$

In response, I think that proponents of the material conception of placement problems can push back against Price's suggestion that semantic notions play an indispensable role in metaphysics. This assumption may seem to be wellsupported if one focuses on the Canberra Plan, with its emphasis on conceptual analysis, but this apparent support fades if one broadens one's survey of contemporary metaphysical methodology to include the work of such philosophers as Penelope Maddy (2007) and Michael Devitt (2010), each of whom do not rely on semantic notions (whether substantive or deflationary) when they do metaphysics. $^{10}$

This response is, of course, programmatic and would require much more argument to flesh out fully. In any case, it is likely that the second horn of Price's dilemma - the lack of a general argument for naturalism - will also pose a challenge to these alternative approaches to metaphysics. This is supported by the fact that naturalistic metaphysics becomes more of a piecemeal, case-bycase affair on Devitt's and Maddy's approaches. (See, e.g. Devitt (2009, 319-20) and Maddy (2007, 402-3).) So, proponents of the material conception will need to blunt this second horn.

Fortunately, I think that they can do so. Price's argument here hinges on the claim that the object naturalist has no advantage over the subject naturalist if she does not have a general argument for her position. I think this is mistaken. For, contra the previous block quotation from Price, important questions about at least some M-worlds remain even after we answer all of the subject naturalist's questions about how we talk in these domains. For instance, even if we

10 See also Stich (1996, 29-82), although he is somewhat skeptical about the prospects for the kind of naturalistic metaphysics he sketches there. 
have answered all questions about the function of our talk about the mental, questions about minds remain that are entirely independent of (and prior to) questions about our use of mental language. ${ }^{11}$ This is reflected in the banal observation that non-human animals had mental states (at least perceptual and affective states) long before language users existed, and they would have had these mental states even if language users never existed. Questions about what these states were like, how they were related to these animals' neural states, and the role these mental states played in the animals' behavioral repertoires are all legitimate questions that have nothing to do with how we happen to talk about mentality. These would remain legitimate, open questions, settled by non-linguistic facts about the world, even if humans did not use language. (Of course, in that case, these questions would go unasked, at least by us.)

Now, Price might respond that all of the questions mentioned above are scientific questions, not metaphysical questions about the mind, and, as such, they are perfectly consistent with a deflationist attitude toward ontology. (His discussion of two interpretations of the question about what makes it true that snow is white suggests this response (2011a, 14).)

I believe that this response again reveals a flawed assumption about the nature of naturalistic metaphysics and its relation to the other sciences, namely, that if naturalistic metaphysics is be viable as a distinct discipline at all, then it must be a relatively formal, logical cum linguistic, endeavor - a kind of second-level project which takes data from the natural sciences as input. It is understandable that Price makes this assumption about the views he opposes, given that, as I discuss in the next section, it follows from Quine's criterion of ontological commitment. However, as I also point out there, naturalists have good reason to reject this criterion.

\section{Quine and Carnap on ontology}

As explicated by Peter van Inwagen, Quine's criterion of ontological commitment is a "set of interrelated theses... about how one should settle philosophical disputes about what there is" $(2009,500)$. Quine's criterion says that participants in ontological debates should regiment the claims they want to affirm into the "quantifier-variable idiom" - first-order logic. Their ontological commitments are

11 While the nature of morality and modality may be constitutively dependent on, and exhausted by, our linguistic and conceptual practices with respect to moral and modal terms, I see little hope of defending the analogous claim with respect to mentality. 
then determined by the existentially quantified sentences that are logical consequences of these regimented claims. If participants are unwilling to accept some of these commitments, they must find alternate renderings of the relevant theses they want to affirm that do not imply the offending existentially quantified statements (cf. van Inwagen 2009, 506). ${ }^{12}$

It is fairly easy to see that Quine's criterion requires a linguistic approach to ontological debates. Quine begins with the truism that we, not sentences or theories, are the primary bearers of ontological commitments $(1948 / 1980,8)$. When he initially characterizes the problem of determining one's ontological commitments he often does so in terms of mental states. For instance, he interprets the question of what is in our ontology as concerning which entities we "assume" (Quine 1981, 2) or "believe in" (Quine 1951/1980, 44, 1981, 21). ${ }^{13}$ But Quine's ontological criterion transforms this from a question about our psychological attitudes toward (purported) entities into a question about which existentially quantified sentences follow from our best theories. So, "what had been a question of assuming objects becomes a question of verbal reference to objects" (Quine 1981, 2, italics added). ${ }^{14}$

Quine's criterion thus entails that the work of the ontologist is a relatively formal, logical, and linguistic endeavor that is posterior to other scientific inquiry. The ontologist goes to work only after the results of other sciences are in; she uses first-order logic to regiment these results in order to display their first-order quantificational structure, after which she can simply read off the ontological commitments of the total theory.

Price's second path from naturalism to ontological deflationism argues that any non-deflationary, object naturalist interpretation of the kind of inquiry that results from Quine's criterion is not naturalistic by Quine's own lights. Thus, he claims that "Quine's own position ... is much closer to Carnap's view than is commonly assumed (2007, 378; see also Alspector-Kelly 2001).

In "Empiricism, Semantics, and Ontology" (1950/1956), Carnap famously claims that any ontological question is ambiguous between a reading that is internal to a linguistic framework and a reading that is external to all frameworks. Internal questions have straightforward answers determined by the

12 Note that Quine here provides a criterion for what a theory says there is, not a criterion for what there actually is.

13 He also writes of which entities we "accept", "acknowledge”, "admit”, "countenance”, "hypostatize", "posit”, "presuppose”, "reify”, or "reckon" (For this list and references see Szabó $(2003,585))$.

14 Quine famously argues for the "indeterminacy of reference" which, given his criterion of ontological commitment, leads to indeterminacy in the ontological commitments of a theory. Neo-Quinean analytic metaphysicians tend to reject Quine's arguments for indeterminacy. 
evidential rules of the relevant framework. However, Carnap claims that any external question “is of a problematic character” (Carnap 1950/1956, 206):

\begin{abstract}
An alleged statement of the reality of the system of entities is a pseudo-statement without cognitive content. To be sure, we have to face at this point an important question; but it is a practical, not a theoretical question; it is question of whether or not to accept the new linguistic forms. The acceptance cannot be judged as being either true or false because it is not an assertion. It can only be judged as being more or less expedient, fruitful, conducive to the aim for which the language is intended. (Carnap 1950/1956, 214)
\end{abstract}

This quotation suggests that deflationism about ontology follows directly from the internal/external distinction. In explicating this idea, Price claims that ontologists commit a use/mention fallacy $(2009,283)$. The only legitimate uses of terms in ontological debates must be internal to a framework (since rough conformity to the rules of a framework constitutes proper use). Legitimate external questions must merely mention the terms in question; they are not about numbers, say, but about how we should employ the term "number".

What should we make of this argument? If we adopt a "thin" interpretation of frameworks according to which they are merely languages or language-fragments, then the conclusion is simply the trivial claim that one cannot ask ontological questions or formulate ontological claims except in a language. ${ }^{15}$ Of course, this is true, but it is not something peculiar to metaphysics, as opposed to any other area of inquiry. More importantly, it does not amount to deflationism about ontology - it does not show that ontological questions are misguided, trivial, or merely verbal or pragmatic disputes.

In short, as Price recognizes, on a thin interpretation of frameworks, this argument simply begs the question against non-deflationary metaphysics by assuming that ontologists must adopt a standpoint external to any linguistic framework. Instead, they can follow Quine and simply claim that they (along with every other inquirer) are working within a single "grand framework," our "web of belief," and that this framework allows for questions to be asked about the fundamental nature and structure of reality (Price 2009, 287). In other words, the thin interpretation of frameworks is compatible with their being a unique best linguistic framework in which to investigate what exists (cf. Eklund 2009, 137).

Note, though, that even this fairly trivial interpretation of the import of the internal/external distinction - that there is no room for ontological investigation

15 For the distinction between thin and thick interpretations of frameworks see Eklund (2009, 132). I, in effect, turn to the question of whether the argument fairs better under a "thick" interpretation of frameworks when I discuss Price's "functional pluralism" below. See note 17. 
outside of our current best scientific theory of the world - is "deflationary" in one good sense, what I'll call minimal deflationism.

Minimal deflationism: Metaphysical inquiry should eschew both "first philosophy," which attempts to provide an independent ground for science, and "two-level" positions according to which philosophy pursues distinctive goals via methods that are autonomous from those of the sciences. ${ }^{16}$

Minimal deflationism, however, does not require, and should not be confused with, ontological deflationism. For, as we'll see in more detail below, it does not require that naturalistic metaphysics must disappear as a distinct discipline, replaced by the other sciences; it does not demand, as Price's ontological deflationism does, that we rest content with "the mundane business of existential quantification carried out by first-order specialists in the course of their working lives."

Up to this point, Carnap's and Quine's views on ontology are very similar. As a result of a shared commitment to minimal deflationism, they both reject a priori constraints on ontology, such as relying on certain intuitions about what does and does not exist when interpreting scientific theories (e.g. the nominalist intuitions that Quine himself once invoked in Quine and Goodman (1947)). On Price's view, however, Carnap's and Quine's paths now diverge temporarily over the issue of whether descriptive language has a single function or multiple functions - over whether functional monism or functional pluralism is true. But, Price claims that, despite this divergence, Carnap and Quine both ultimately end up in the same place, with a deflationary approach to ontology.

Price claims that Carnap is at least implicitly committed to the functional pluralist view that I mentioned in the introduction (2009, 283; 2011a, 13). Using functional pluralism, Price argues that Carnap can block Quine's “single, grand framework" response (outlined above) to the argument for ontological deflationism that is based simply on the internal/external distinction (2009, 289ff.). ${ }^{17}$ Now, whether or not functional pluralism is true is ultimately an empirical matter about which the jury is still out (1992, 45; 2009, 293-4). Thus, I obviously cannot offer a knockdown argument against it here. But, even if functional

16 Minimal deflationism captures the naturalistic tenor of some of Carnap's writings. See, e.g. his $(1934 / 1937,332)$.

17 Price claims that the primary issue between functional monists and functional pluralists is whether there is a coherent, framework-independent characterization of factual discourse (1992, 44-6). So, adopting functional pluralism pretty clearly amounts to invoking a "thick" interpretation of linguistic frameworks, according to which truth and factuality are relative to a framework and the question of whether a statement is true or factual, independently of any framework, cannot even be raised. On the "thick" interpretation of frameworks, see Eklund (2009, 132). 
pluralism is true in some form, it is far from clear whether this form will support deflationary metaphysics. For instance, as Price himself points out, it is not clear whether the empirical study of language will yield functional criteria that will individuate frameworks in the way that the ontological deflationist requires (1997, 147; 2009, 293).

Thus, the route to from naturalism to deflationary metaphysics via functional pluralism is far from smooth, but I admit that, for all I've said in this paper, it remains open. More importantly for current purposes, Price believes that any other route that is open to naturalists also leads to ontological deflationism. In the next two sub-sections, I argue that he is wrong about this. Non-deflationary naturalistic metaphysics remains a viable option, but only if we recognize that there are naturalistic reasons to depart significantly from "mainstream, Quinean" metaphysics - by rejecting Quine’s criterion of ontological commitment.

\title{
Blocking the move from minimal deflationism to ontological deflationism
}

The following passage nicely captures the two-stage nature of Quine's approach to ontology:

\begin{abstract}
Instead of asking, first, what there really is or could really be, and then shaping scientific doctrine in order to conform to that determination, we first ask what the best scientific doctrine is to date, and then determine what that doctrine says there is by asking what entities must exist for it to be true. The first move is naturalism. Scientific inquiry being the best, and indeed the only, epistemological game in town, we can do no better than endorse its results with no more reservation than scientific fallibility in general allows. The second move is the application of his criterion of ontological commitment. (Alspector-Kelly 2001, 114)
\end{abstract}

Now, Price distinguishes between two ways of interpreting Quine's criterion of ontological commitment. On the first, “thin” reading, Quine's principle is simply an affirmation of ontological deflationism - simply acquiescence in what "firstorder specialists" - tell us there is $(1992,50)$. On the second, "thick" reading, the activities of first-order specialists is taken to be "raw data" for the second-order science of ontology: the fact that specialists quantify over entities of a certain kind is taken to be evidence that these entities actually exist (1992, 50). In a more recent paper, Price admits that these readings are caricatures, and he explores three strategies for "beefing up" the thin version into something with a more active, and realistic, role for philosophy: ontologists could focus on truthmakers, the interpretation of scientific theories, or the quantificational structure of theories $(2007,384)$. But, Price points out, it is naturalistically unacceptable for any 
of these strategies to involve a two-stage process in which one first does the science and then steps outside science to figure out how things really are. Thus, Price claims, "only the thin reading can really be regarded as legitimate by Quine's own lights” (2007, 382).

Take a particular example. Assuming that number theory is part of our current best total science, we can run the following "cheap argument”:

There is an even prime.

Primes are numbers.

Therefore, numbers exist. ${ }^{18}$

As Zoltan Gendler Szabó has pointed out $(2003,590)$, if ontological debates are debates about what we should quantify over, then there are only three responses one can have to such an argument: (1) Accept the argument as sound, and take the relevant ontological question to be settled. (2) Reject one of the premises. (3) Claim that the argument equivocates and that it is invalid (or if it is valid and settles the ontological question, it does so only on a disambiguation that requires additional argument for at least one of the premises).

Most nominalists (and Platonists who engage in debate with them) take the third option. ${ }^{19}$ Mainstream analytic metaphysicians also typically take this option when they want to deny ontological commitment to some kind of entity or other. Roughly, such philosophers claim that the first premise and conclusion are clearly true in an ontologically innocent "loose and popular" sense of "exist" or "there are". However, this sense is not what is at issue in ontological debates. When we do ontology we care about the "strict and philosophical" sense of 'exist' or 'there are,' and taken in this sense, the first premise (and conclusion) is either false or is not something that is settled by number theory (or science in general) alone (cf. Sider's discussion of introducing the language Ontologese for use in the metaphysics room (2011, 171ff.)). The third option thus amounts to one of Price's "thick" readings of Quinean meta-ontology, all of which take the conclusion of cheap arguments to be merely data that do not settle ontological questions. I think that Price is right to reject these views as in tension with naturalism.

18 Cheap arguments can be given for the existence of other entities about which there is debate in analytic metaphysics: e.g. ordinary, macroscopic objects, like tables (from premises supported not only by "common sense" but also by solid-state physics), mental states (from premises supported by cognitive psychology), or events (from premises supported by linguistics).

19 As Alspector-Kelly writes, empiricist/nominalist critics of Carnap know that “... when one is engaged in mathematics, denial of 'There is an even prime' evinces mathematical incompetence rather than ontological restraint. But that, of course, is not taken to decide the ontological issue, which concerns the fidelity of quantification over numbers to reality” $(2001,105)$. 
Further, the second option is unattractive, since as Szabó notes, it threatens to make ontological inquiry "futile" $(2003,591)$. If we deny such obvious claims as the premises of cheap arguments, we run the risk of losing track of what we arguing about and of merely talking past our opponents. So, naturalists seem to be stuck with the first option, which amounts to ontological deflationism. For, as Szabó notes, the first option makes ontological inquiry "vacuous," (2003, 591): "if ontological debates can be so readily resolved, then they seem to be unsuitable for serious philosophical inquiry" (2003, 589).

Szabó takes this to be a cost, but ontological deflationists think it is a virtue. Szabó complains that: "It is not irrational to take a skeptical or outright eliminativist stance towards [numbers], even if it is in the end incorrect to do so" (2003, 589). Ontological deflationists would reply that questions of (frameworkindependent) rationality or correctness do not even arise; to think otherwise is to take factual, external ontological questions to be legitimate. On their view, such questions are not suitable for serious philosophical inquiry; they are pragmatic matters of choosing a linguistic framework.

So, minimal deflationism seems to leave us with the "thin" reading of Quinean meta-ontology and thus with ontological deflationism (Price 2007, 389). Note, however, that taking the first option with respect to "cheap arguments" has two parts: (i) accepting these arguments as sound (i.e. the first, naturalistic move in the block quotation from Alspector-Kelly above, which is required by what I've called minimal deflationism) and (ii) taking such arguments to settle ontological disputes (i.e. the second move in the passage from Alspector-Kelly - Quine's criterion of ontological commitment). It is only these two parts together that take us all the way to ontological deflationism. Similarly, Price's claim that the "thin" and three "thick" readings of Quine's doctrine of ontological commitment exhaust the options available to the naturalistic metaphysician presupposes that Quine's doctrine of ontological commitment is true.

Thus, if we reject Quine's doctrine of ontological commitment, i.e. if we deny that believing that there are Xs (i.e. quantifying over Xs) amounts to fullblown ontological commitment to Xs, then another option opens up: we can accept cheap arguments as sound, without taking the relevant ontological questions to be thereby settled (cf. Szabó 2003, 591). This makes room for a non-deflationary conception of naturalistic metaphysics - a way of defending object naturalism - that avoids Price's false dilemma between a "thin" metaphysics that merely acquiesces in the ontological verdicts of the other sciences and a "thick" metaphysics that uses only logical methods of regimentation and supposedly stands outside of science altogether. Instead, as I outline in the final main section, "A sketch of non-deflationary naturalistic metaphysics", it is a truly multi-disciplinary endeavor, drawing on and synthesizing the results of 
many disciplines, including the history and philosophy of science, using the skills which philosophical training provides.

\section{Naturalistic reasons to reject Quine's criterion of ontological commitment}

We've seen that naturalists have two pragmatic reasons to reject Quine's criterion: first, to avoid a linguistic approach to metaphysics that must face the challenges to Representationalism if it is to be non-deflationary; second, to avoid the charge that the only options for a non-deflationary metaphysics are not naturalistically acceptable. There are at least two lines of thought that also provide naturalists with good evidential reasons to reject Quine's criterion.

First, Quine's criterion implies that any remaining difference between the question of "assuming objects" (or "believing in objects") and the question of "verbal reference to objects" (or "quantifying over objects") is insignificant for the purposes of ontological debates (cf. Szabó 2003, 585). Naturalists should be suspicious of this claim given that it is, at least in part, motivated by Quine's behaviorism and the accompanying abhorrence of intentional mental states, both of which are now widely (and rightly in my view) regarded as scientifically suspect. Absent these motivations, I can see no good reason to think that the difference between these questions can be safely ignored. For one thing, all of the evidence that supports semantic externalism suggests that it is fairly easy to refer to things in the world (e.g. via deference to experts), but it is far from clear if ontological commitments can be accrued so easily. In fact, Szabó $(2003,2010)$ has given strong arguments for the idea that we cannot safely ignore the difference between believing in (or being ontologically committed to) things and referring to (or quantifying over) them - that it is not enough to quantify over a purported entity in order to assert an ontological commitment to it. ${ }^{20}$

20 Szabó's (2003) begins with a quotation from a book on mythological creatures that suggests that some scientists rationally believed that the term "sea serpent" refers to something in the oceans while withholding ontological commitment to sea serpents. In the 2010 paper, Szabó claims that he stands by his conclusions in his (2003) but now provides a different argument for them because he has "grown dissatisfied that they [were] so tightly connected to semantic considerations" (2010, 39 n. 13). Szabó does not elaborate on the reasons for this dissatisfaction; my discussion above shows that it is justified if one wants to remain a naturalist while avoiding ontological deflationism. Roughly, on Szabó's view, ontological commitment to Xs requires believing that Xs exist and being able to explain why Xs exist, which requires knowing what the nature of Xs is. 
Second, and perhaps more importantly, as Penelope Maddy has argued, Quine's criterion does not adequately portray how rational debates about ontology have actually been conducted in the sciences (e.g. 1997, 135-43; 2007, 95-7, 398-407). She claims that both (a) work on atomic theory at the turn of the twentieth century and (b) the nature of idealization and mathematization in science suggests that: "Pace Quine, determining what our successful theories tell us about what there is cannot be a simple matter of reading off their existential claims" $(2007,107) .{ }^{21}$ Rather, “a consistent naturalist must recognize various different types of evidence and various different roles hypotheses can play in our theorizing" when she is engaged in ontological debates $(2007,96$; see also 316-17).

Maddy frames her critique of Quine as aimed primarily at his confirmational holism (e.g. 2007, 95). However, she apparently does not see much, if any, substantive difference between her way of putting things and one that takes aim directly at Quine's criterion of ontological commitment (1997, 143; 2007, 95 n. 20). ${ }^{22}$ I suggest that Maddy's argument is best interpreted as motivating a position similar to Szabó's, according to which scientists in 1900 were right to believe that there are atoms but also correct to withhold ontological commitment to atoms (in this case because detection of atoms (a new type of evidence altogether) awaited the work of Jean Perrin). But whether we deny that entire theories are confirmed as a unit or deny that we are committed to everything that our theories quantify over, the important point for my purposes is that either critique undermines the idea that we can simply read ontological commitments off of what a theory says there is.

\section{A sketch of non-deflationary naturalistic metaphysics}

So far I've said very little about what an alternative, non-deflationary naturalistic metaphysics would look like. Fully developing this alternative approach is a project for another occasion, but in conclusion I want to sketch some of its features by drawing on the lessons learned from my critique of Price.

21 van Fraassen (2009) has recently argued that Jean Perrin's work on Brownian motion, which Maddy crucially relies on, does not support naturalistic realism about atoms of the kind Maddy (and I) endorse. Chalmers (2011) responds to van Fraassen.

22 Maddy (1996, 333; 1997, 143) also suggests that her critique might be taken to be aimed at the univocality of either "there is" or the existential quantifier (both of which are fundamental tenets of Quinean meta-ontology (van Inwagen 2009)). 
Those who approach metaphysics from a naturalistic yet non-deflationary perspective must endorse minimal deflationism, which I suggest is a core element of any naturalistic position. As we've seen above, they also should approach metaphysical questions from the material conception. I think that the best way of satisfying these constraints is to think of naturalistic metaphysics as itself a "first-order" science alongside the other sciences. This implies that if we accept the slogan that "science tells us what to believe in," we are not asserting what this slogan is often taken to mean. In particular, we are not claiming that physics, psychology, chemistry, biology, etc., taken on their own, individually or collectively, tell us what to believe in. Rather, the science of naturalistic metaphysics typically tells us what to believe in.

It is not that naturalistic metaphysicians have some exclusive ownership of ontological questions, nor do they have some special methods of determining what we do, or should, believe in. Rather, they synthesize and reflect upon (and in some cases, correct ${ }^{23}$ ) the methods and results from a wide variety of scientific disciplines, using the skills that training in (naturalistic) philosophy is particularly well suited to provide. ${ }^{24}$ In straightforward cases, the work they do could be done by many scientifically literate people (see, e.g. Maddy on the existence of "medium-sized physical objects" (2007, 403-4)). But in difficult cases, they simply apply these same reliable scientific methods in ways in which other scientists typically do not and typically don't have the training for (cf. Maddy 2007, 115, 407). For instance, giving a detailed account of why some scientists believed in atoms in 1910, but not in 1900, and why they were correct to do so, will involve synthesizing and critically reflecting on results from (at least) physics, chemistry, applied mathematics, and perceptual psychology. And, examining whether we should be ontologically committed to intentional states or conscious states will involve synthesis of, and reflection on, work from (at least!) biochemistry, neuroanatomy and neurophysiology, psychophysics, cognitive neuroscience, cognitive and social psychology, linguistics, and sociology. In any case, from the approach of the material conception, Price is certainly wrong to think that we can stop with a linguistic investigation of the way we talk about atoms, beliefs, or conscious states.

If the work I drew on in the previous subsection ("Naturalistic reasons to reject Quine's criterion of ontological commitment") is on the right track, then our inquirers also need to reject the Quinean criterion of ontological

23 Maddy mentions feminist critiques of primatology in this regard $(2007,407)$.

24 Note that naturalists will claim that the interpretation of scientific theories is part of science itself and does not require a kind of reasoning that is completely independent of the way we have discovered the world to be. 
commitment in order to fully realize the goal of naturalizing non-deflationary metaphysics. Rejecting Quine's criterion also allows us to offer oblique answers to some ontological questions - by allowing that the entities in question exist (quantifying over them) while denying ontological commitment to them (cf. Szabó 2003, 607-9; 2010, 36-8). For instance, this kind of view might be currently motivated by our best current theories of conscious states. The fact that there are many obvious true claims about such states entails that there are conscious states. But, on this view, this is compatible with either (1) our current best account of consciousness being mistaken about its nature or (2) currently being unable to detect conscious states in an appropriate way (cf. Schwitzgebel 2011), either of which, on different versions of such a view, would warrant withholding ontological commitment to conscious states.

It is possible that this kind of oblique answer is the best that we can ever give to some ontological questions. For example, it might be the best that we can say about beliefs if folk psychology is radically mistaken, for in that case there might be no fact of the matter about what beliefs really are. ${ }^{25}$ In any case, I think that the fact that this kind of oblique response is available to non-deflationary naturalistic ontologists allows them to capture the kernel of truth in full-blown ontological deflationism. It allows one to accept the "cheap arguments" that ontological deflationists are so fond of without claiming that there is nothing left for metaphysicians to do.

I have argued that Price is wrong to think that naturalists must adopt a deflationary, linguistic approach to ontology. However, grappling with his rich and provocative work has shown that naturalists who wish to pursue a more substantive approach to metaphysics cannot simply rest content with mainstream, “Quinean” metaphysics. What's more, I've suggested that departing from the mainstream, by rejecting Quine's criterion of ontological commitment, enables such naturalists to capture whatever salutary motivations lie behind Price's own deflationary approach to ontology.

Acknowledgment: I presented an earlier version of some of this material at the Metaphysics and Philosophy of Science Conference in Toronto (May 2011) and the American Philosophical Association Pacific Division meeting in Seattle (April 2012). Thanks to the audiences on those occasions, and to my commentator at the latter, Troy Cross, for helpful comments and discussion.

25 Devitt also suggests that some ontological questions may not have determinate answers and uses the existence of intentional states as an example (2009, 319-20). 


\section{References}

Alspector-Kelly, M. 2001. “On Quine on Carnap on Ontology.” Philosophical Studies 102: 92-122.

Carnap, R. 1934/1937. Logical Syntax of Language. London: Kegan Paul, Trench, Trubner. Carnap, R. 1950/1956. Empiricism, Semantics and Ontology. Reprinted in his Meaning and Necessity. 2nd ed., 205-21. Chicago: University of Chicago Press.

Chalmers, A. 2011. “Drawing Philosophical Lessons from Perrin's Experiments on Brownian Motion: A Response to Van Fraassen." British Journal for the Philosophy of Science 62:711-32.

Devitt, M. 2009. “On Determining What There Isn't.” In Stich and His Critics, edited by D. Murphy and M. Bishop, 46-61. Chichester: Wiley-Blackwell. Reprinted in Devitt (2010), 303-20.

Devitt, M. 2010. Putting Metaphysics First. Oxford: Oxford University Press.

Eklund, M. 2009. “Carnap and Ontological Pluralism.” In Metametaphysics, edited by D. J. Chalmers, D. Manley, and R. Wasserman, 130-56. Oxford: Oxford University Press.

Ismael, J. 2013. "Naturalism on the Sydney Plan.” In Philosophical Methodology: The Armchair or the Laboratory? edited by M. C. Haug, 86-104. New York: Routledge.

Jackson, F. 1998. From Metaphysics to Ethics. Oxford: Oxford University Press.

Maddy, P. 1996 “Ontological Commitment: Between Quine and Duhem.” Philosophical Perspectives 10:317-41.

Maddy, P. 1997. Naturalism in Mathematics. New York: Oxford University Press.

Maddy, P. 2007. Second Philosophy. New York: Oxford University Press.

Manley, D. 2009. "Introduction: A Guided Tour of Metametaphysics." In Metametaphysics, edited by D. J. Chalmers, D. Manley, and R. Wasserman, 1-37. Oxford: Oxford University Press.

Price, H. 1992. “Metaphysical Pluralism.” Journal of Philosophy 89:387-409. Reprinted in Price (2011b), 34-53.

Price, H. 1997. "Naturalism and the Fate of M-Worlds." Proceedings of the Aristotelian Society, Supplement 71:247-67. Reprinted in Price (2011b), 132-47.

Price, H. 2004. "Naturalism without Representationalism." In Naturalism in Question, edited by M. De Caro and D. Macarthur, 71-88. Cambridge, MA: Harvard University Press. Reprinted in Price (2011b), 184-99.

Price, H. 2007. “Quining Naturalism.” Journal of Philosophy 104:374-402.

Price, H. 2009. “Metaphysics After Carnap: The Ghost Who Walks?” In Metametaphysics, edited by D. J. Chalmers, D. Manley, and R. Wasserman, 320-46. Oxford: Oxford University Press. Reprinted in Price (2011b), 280-303.

Price, H. 2011a. “Moving the Mirror Aside.” In Price (2011b), 3-33. Oxford: Oxford University Press.

Price, H. 2011b. Naturalism without Mirrors. Oxford: Oxford University Press.

Quine, W. V. O. 1948/1980. “On What There Is.” Reprinted in his From a Logical Point of View, 1-19. Cambridge, MA: Harvard University Press.

Quine, W. V. 0. 1951/1980. Two Dogmas of Empiricism. Reprinted in his From a Logical Point of View, 20-46. Cambridge, MA: Harvard University Press.

Quine, W. V. O. 1981. "Things and Their Place in Theories.” In Theories and Things, 1-23. Cambridge, MA: Harvard University Press. 
Quine, W. V., and N. Goodman. 1947. "Steps Toward a Constructive Nominalism.” Journal of Symbolic Logic 12:105-22.

Schwitzgebel, E. 2011. Perplexities of Consciousness. Cambridge, MA: MIT Press.

Sider, T. 2011. Writing the Book of the World. Oxford: Oxford University Press.

Stich, S. 1996. Deconstructing the Mind. Oxford: Oxford University Press.

Szabó, Z. G. 2003. "Believing in Things." Philosophy and Phenomenological Research 66: 584-611.

Szabó, Z. G. 2010. "The Ontological Attitude." In The Analytic Way: Proceedings of the 6th European Congress of Analytic Philosophy, edited by T. Czarnecki, K. Kijania-Placek, 0 Poller, and J. Woleński, 21-42. London: King's College Publications.

Thomasson, A. 2013. "The Easy Approach to Ontology." In Philosophical Methodology: The Armchair or the Laboratory? edited by M. C. Haug, 107-25. New York: Routledge.

van Fraassen, B. 2009. "The Perils of Perrin, in the Hands of Philosophers." Philosophical Studies 143:5-24.

van Inwagen, P. 1998. “Meta-Ontology.” Erkenntnis 48:233-50.

van Inwagen, P. 2009. "Being, Existence, and Ontological Commitment." In Metametaphysics, edited by D. J. Chalmers, D. Manley, and R. Wasserman, 472-506. Oxford: Oxford University Press. 
Copyright of Metaphysica is the property of De Gruyter and its content may not be copied or emailed to multiple sites or posted to a listserv without the copyright holder's express written permission. However, users may print, download, or email articles for individual use. 